\title{
NONDESTRUCTIVE TEST TECHNOLOGY RESEARCH FOR YARN LINEAR DENSITY UNEVENNESS
}

\author{
Bin Zhou ${ }^{1,2,3 \dagger}$, Huiling Wang ${ }^{1,2,3 \dagger}$, Ke Wang ${ }^{1,3}$, Jumei Zhao ${ }^{1,3}$, Hongtao Zhou ${ }^{1,3}$, Shihui Huang ${ }^{1}$ \\ 1 School of Textiles and Clothing, Yancheng Polytechnic College, Yancheng 224005, P.R. China \\ 2 College of Textile Science and Engineering International Institute of Silk $\rrbracket$, Zhejiang Sci-Tech University, Hangzhou 310000, P.R. China. \\ 3 Jiangsu Province Engineering Research Center of Biomass Functional Textile Fiber Development and Application, Yancheng 224005, P.R. China. \\ *Corresponding author: sanlin2007@126.com
}

†These authors contributed equally to this work

\begin{abstract}
:
Yarn linear density and linear density unevenness between fragments involve the mass and mass variation of yarn per unit length, which are important indices to reflect the uniformity of yarn thickness. Aiming at the shortcomings of the traditional testing method, which uses a yarn length tester to test these indices by counting length first and then cutting and measuring weight, a testing device that measures weight and counts length synchronously is designed and developed, so that the yarn can be continuous, recyclable, and reusable. Length counting is conducted by a length-counting disk connected to a photoelectric coded disk, and the result of length counting can be accurate to $0.01 \mathrm{~m}$. The original skein frame with a perimeter of $1 \mathrm{~m}$ is replaced, so that the error caused by yarn overlapping is avoided. Through program control, the testing of a plurality of groups of linear density values can be completed at one time to calculate the linear density unevenness of different fragments of yarn, and the yarn can be led to a recovery spool through a yarn guide cylinder to form a new package. Polyester/viscose 65/35 blended yarn was taken as a test sample and subjected to statistical analysis using SPSS software. It is found that the results of the newly developed device are closer to the arbitration value; the whole experiment is completed at one time, which avoids the secondary error and reduces the labor intensity; and the raw materials can be recycled, which saves labor and raw material costs. The device has high value for industrialization and popularization.
\end{abstract}

\section{Keywords:}

Yarn linear density, fragment unevenness, weight measurement, length counting, synchronization testing, nondestructive recovery

\section{Introduction}

Yarn is a semi-finished textile product, and its fineness and fineness unevenness are essential to the physical and mechanical properties, hand feeling, style, and other performance aspects of textiles [1]. They are important indices for the testing of conventional structural parameters of textile products and important bases for product design. Yarn fineness can be expressed in terms of yarn diameter, crosssectional area, and linear density [2-4]. Linear density is a physical quantity that represents the mass of an object per unit length. Because yarn is a flexible body, which has filoplume on the surface and irregular cross-section and is easy to deform under the influence of external forces, the yarn thickness expressed by diameter involves its apparent diameter under certain bulky conditions $[5,6]$. The measurement of crosssectional area of yarn is time-consuming and laborious, and it is troublesome to make slices [7]. Therefore, the yarn fineness is often expressed by linear density in practice. The length and weight of yarn must be measured during the testing of yarn linear density, which is called a length-counting and weightmeasuring method, and also called a cutting and weight- measuring method. In general, yarn of a specified length is taken as a test unit, and is dried, weighed, and converted into a mass value under commercial moisture regain, so that the yarn linear density can be calculated [8-11]. Unevenness of linear density between yarn fragments translates to mass variation of yarn per unit length, and is an important index to reflect the uniformity of yarn thickness. The length-counting and weightmeasuring method is also the most basic and simplest method for measuring the uniformity of yarn thickness, especially the unevenness of medium- and long-fragment yarn. In this method, the yarn to be tested is cut into the required number of fragments with the length as similar to each other as possible, according to the actual situation and the requirements of test accuracy. The fragments are weighed, respectively, and then the mean difference unevenness $\mathrm{H}$ (mean difference coefficient), the average variance coefficient $\mathrm{CV}$, and the range coefficient $\mathrm{J}$ are calculated using the characteristic indices that measure the discreteness in mathematical statistics [12-14]. At present, the fineness unevenness of strips, rough yarn, and fine yarn is generally determined by the length-counting and weight-measuring method in textile mills, which can detect the mass unevenness of yarn fragments of various lengths. This method is still widely used in general productive long-fragment 
testing, and has important application value for the research requiring high accuracy, the correction of readings of other unevenness testing devices, and the comprehensive analysis and evaluation in conjunction with other devices [15-17].

In accordance with the requirements of relevant testing standards such as GB/T4743 Textiles - Yarn from packages - Determination of linear density (mass per unit length) by the skein method (China) and ISO 2060 Textiles - Yarn from packages - Determination of linear density (mass per unit length) by the skein method, a yarn length tester is often used for length counting and weight measurement of yarn (cutting and weight-measuring method) (Figure 1). However, this testing method has the following defects: 1. The length counting is not accurate. As can be seen from Figure 1(a), the skein frame with a perimeter of $1 \mathrm{~m}$ is used for yarn winding; the yarn on the skein frame overlaps seriously as the number of winding turns increases; as a result, the actual testing length of the sample is excessive, and the final experimental results are also excessive. 2. Length counting and weight measurement are carried out separately. After being wound to the set number of turns, the yarn shall be cut off from the frame and then put on an electronic balance for weighing. It is easy for this to result in secondary error. For the experiment of linear density unevenness, 30 to 50 groups of data need to be independently tested, which takes a long time and has high labor intensity. 3 . Yarn fragments of different lengths can be obtained by setting the number of turns of the device according to the actual needs, but due to the limitation of the perimeter of the yarn frame, it is not possible to obtain yarn fragments of less than 1 $\mathrm{m}$ long. 4. Raw materials cannot be recycled, leading to serious waste. The reeled yarn is twisted into a ball after being cut off
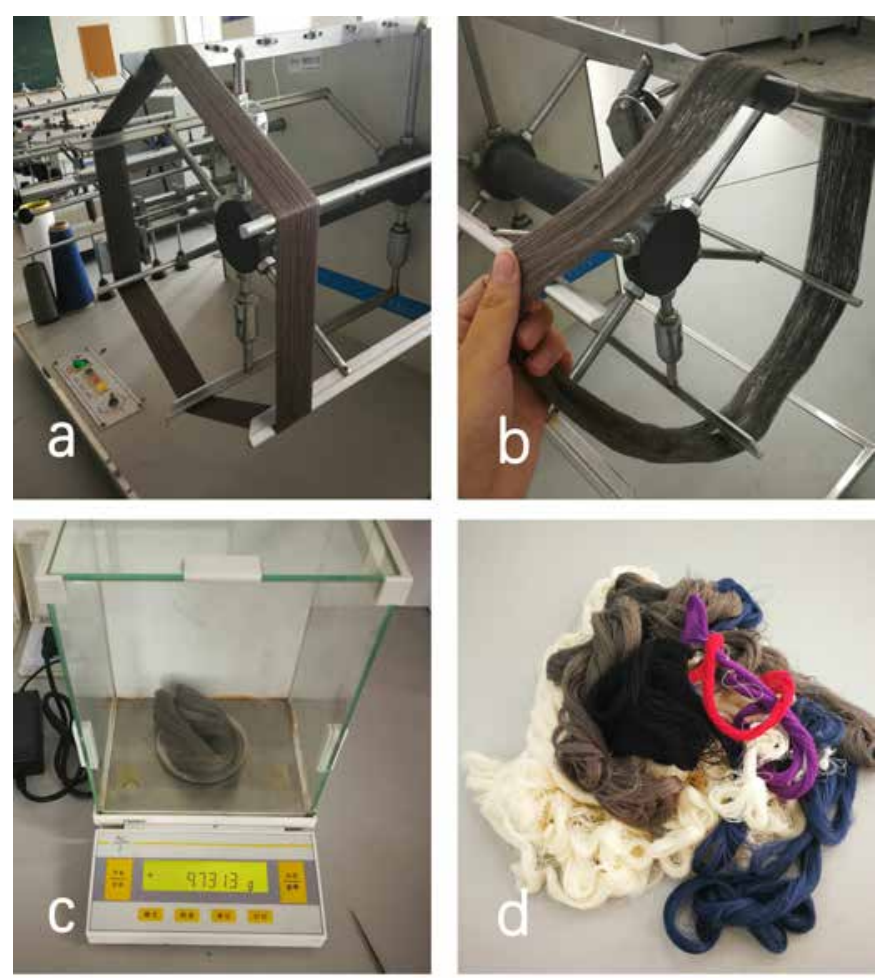

(a) reeling yarn, (b) removing yarn, (c) weighing yarn, (d) discarding yarn

Figure 1. Length-counting and weight-measuring using yarn length tester and weighed. It is basically not worth recycling for utilization and can only be treated as waste yarn, which results in serious waste of raw materials.

In this paper, a testing device for linear density and linear density unevenness that "measures weight and counts length synchronously, and is nondestructive, keeping yarn continuous, recyclable and reusable" is designed and developed to solve such problems as "inaccurate length counting due to yarn overlapping, and discontinuous and non-recoverable yarn due to separate length counting and weight measurement" in the process of length counting and weight measurement of the yarn length tester. Typical yarn samples are tested and analyzed.

\section{Experimental Design}

\subsection{Machine design}

The functional units of the device are designed following the idea that "the weight is measured first and then the length is counted, the weight measurement and length counting are carried out synchronously and completed at one time, and nondestructive recovery of the yarn can be realized." As shown in Figure 2 and Figure 3, the device mainly consists of four parts, including an electronic weight measurement unit, an electronic length-counting unit, a yarn recovery unit and a computing control unit. Among them, the electronic weight measurement unit and the electronic length-counting unit send the mass and length values of a yarn sample under testing to the computing control unit before and after winding, respectively, for linear density and linear density unevenness index conversion, and the yarn recovery unit re-rolls and recycles the wound yarn.

(1) Electronic weight measurement unit. The core component of this unit is an electronic balance, which transmits the values of the mass of bobbin yarn or cheese yarn before and after winding to the computing control unit. The electronic balance has an accuracy of $0.01 \mathrm{~g}$ and a range of $2200 \mathrm{~g}$, which meets the mass requirements of conventional cheese yarn or other rolled yarn.

(2) Electronic length-counting unit. Figure 4 and Figure 5 show the electronic length-counting unit. The unit consists of a length-counting device, above and below which there is a yarn tension device and a yarn guide hook, respectively. The length-counting device has a length-counting disk, which is connected to a photoelectric coded disk through a rotating shaft. The coded disk has a resolution of 50 , and is able to accurately count the number of turns of the length-counting disk, and the counting result can be accurate to 0.02 turn. The coded disk of a different resolution can also be used according to a different test accuracy requirement. The length-counting disk replaces the original skein frame with a perimeter of 1 $\mathrm{m}$ of the yarn length tester, which avoids the error caused by yarn overlapping. The periphery of the length-counting disk is designed as a groove, the perimeter of the groove is $30 \pm 0.1$ $\mathrm{cm}$, and the friction coefficient of the groove is relatively large. The length-counting disk is provided with a pair of yarn tension devices and a pair of yarn guide hooks which hold the yarn to be 


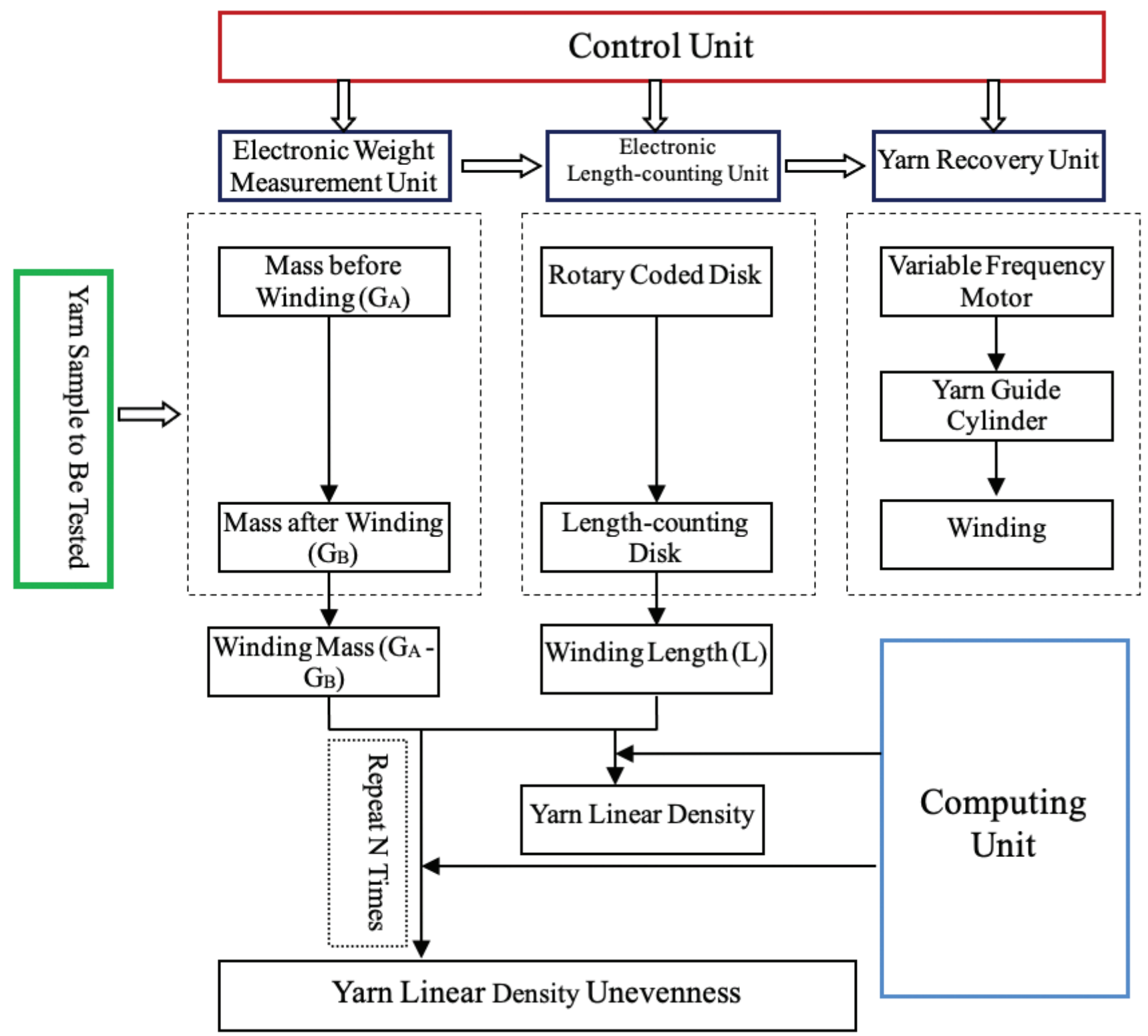

Figure 2. Design frame chart of device

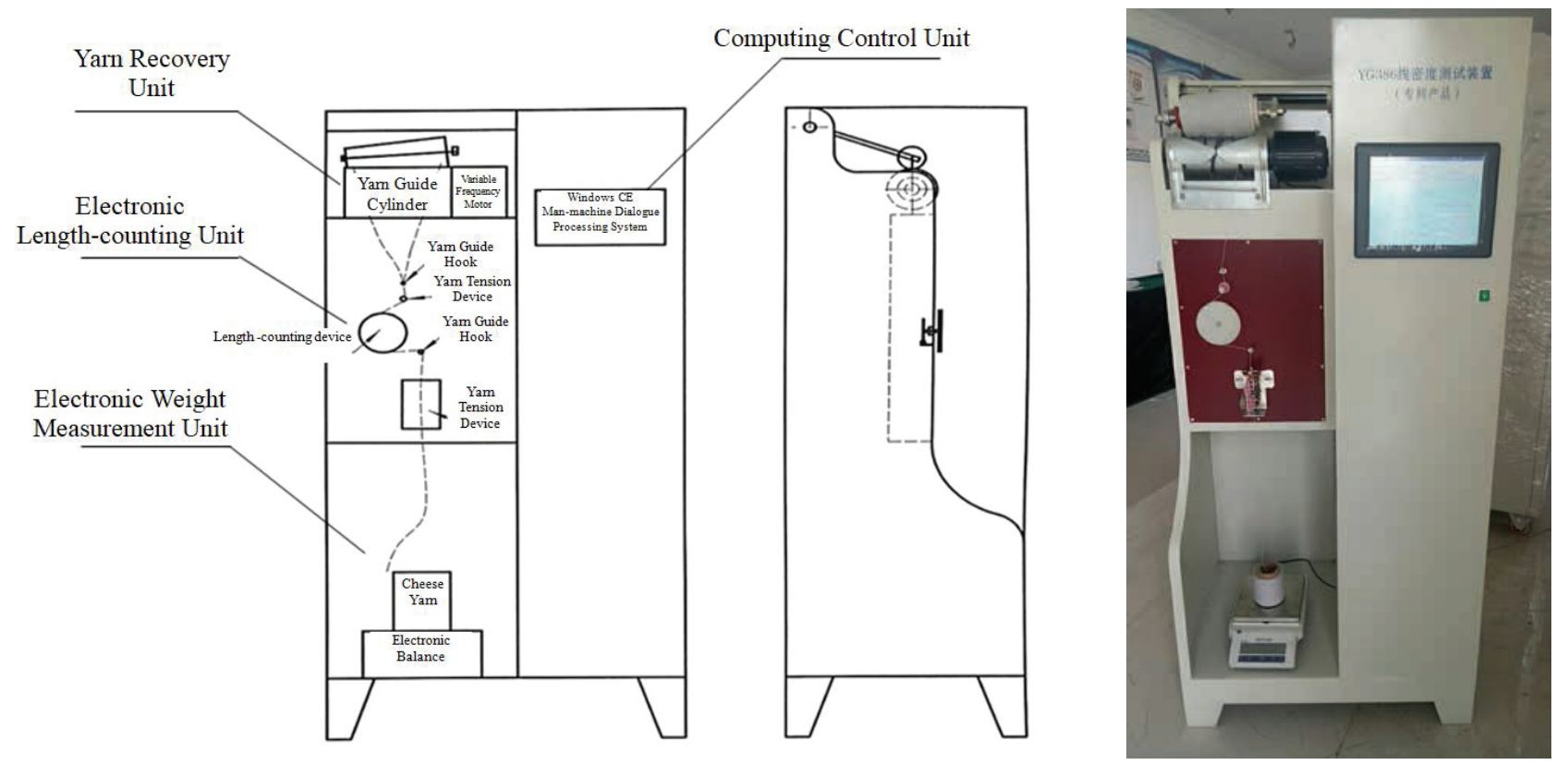

Figure 3. Device appearance structure chart (left: main view, middle: side view, right: physical picture) 
tested, so as to prevent the yarn in the groove from loosening and slipping and ensure the accuracy of length counting. The actual winding length is the product of the number of turns of the length-counting disk and the perimeter of the groove. Before weighing with the balance, the tension of the lower yarn tension device is released to ensure that the yarn is loose and prevent tension on the yarn from interfering with the weighing of the electronic balance, so as to avoid excessive results.

(3) Yarn recovery unit. This unit is the source of power throughout the testing. As shown in Figure 6, the unit consists of a yarn guide cylinder, a spool, and a variable frequency motor. The yarn guide cylinder is connected to the variable frequency motor through a rotating shaft, and the variable frequency motor controls the rotational speed of the yarn guide cylinder. During winding, the yarn guide cylinder rotates at a high speed, and drives the spool to rotate by its surface friction. The surface of the yarn guide cylinder is provided with closed left and right spiral grooves, which can guide the yarn to reciprocate along the axial direction of the spool, so as to achieve uniform winding around the spool and finally form a good package.

(4) Computing control unit. With a Windows CE human-machine dialogue processing system for program control, the electronic weight measurement unit transmits the data of the electronic balance before and after yarn winding to the computing control unit in real time, the electronic length-counting unit transmits the collected number of turns of the length-counting disk to the computing control unit, which can be completed automatically, and the computing control unit automatically calculates the yarn linear density and linear density unevenness according to the input experimental parameters.

\subsection{Testing methods}

The testing of yarn linear density and linear density unevenness mainly includes the following steps:

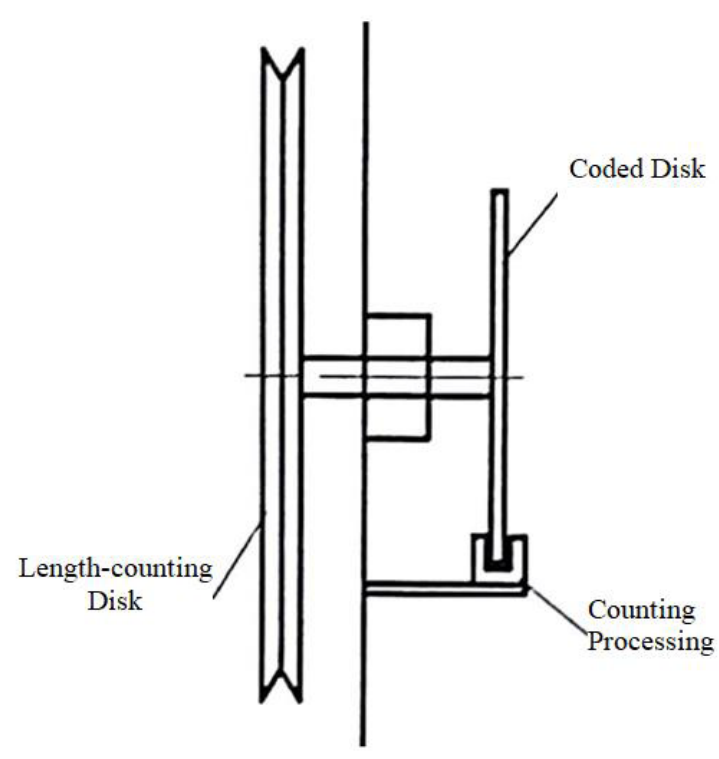

Figure 4. Schematic diagram of electronic length-counting unit
1. Power-on self-test and automatic zero setting of the electronic balance. Input basic parameters to the computing control unit to set the winding length and the number of times of testing.

2. Put bobbin yarn or cheese yarn to be tested on the weighing disk of the electronic balance, lead out the thrum, discard the first 2 to 3 meters of thrum, pass the yarn through the yarn tension device (lower), the yarn guide hook (lower), the lengthcounting disk, the yarn tension device (upper) and the yarn guide hook (upper) successively, and then guide the yarn to the recovery spool through the yarn guide cylinder. Adjust the yarn tension device according to GB/T4743-2009 (China), and set the yarn tension, so as to ensure that the yarn is straight but not elongated.

3. Transmit the mass $G_{f}$ of the yarn sample to be tested before winding to the computing control unit after the electronic balance is stabilized.

4. The computing control unit drives the variable frequency motor to operate, the variable frequency motor drives the yarn guide cylinder to draw yarn, and the yarn drives the lengthcounting disk to rotate. The number of turns of the lengthcounting disk is obtained by the coded disk, and the data are transmitted to the computing control unit. The actual winding length is the product of the number of turns of the lengthcounting disk and the perimeter of the groove. When the winding length is 10 meters shorter than the set length, the variable frequency motor is made to operate at a low speed (20 r/min) until the winding length reaches the set value, so as to avoid excessive winding of yarn. Whenever the electronic balance is used to measure the mass, the lower yarn tension device falls down to relax the tensioned yarn, ensuring that
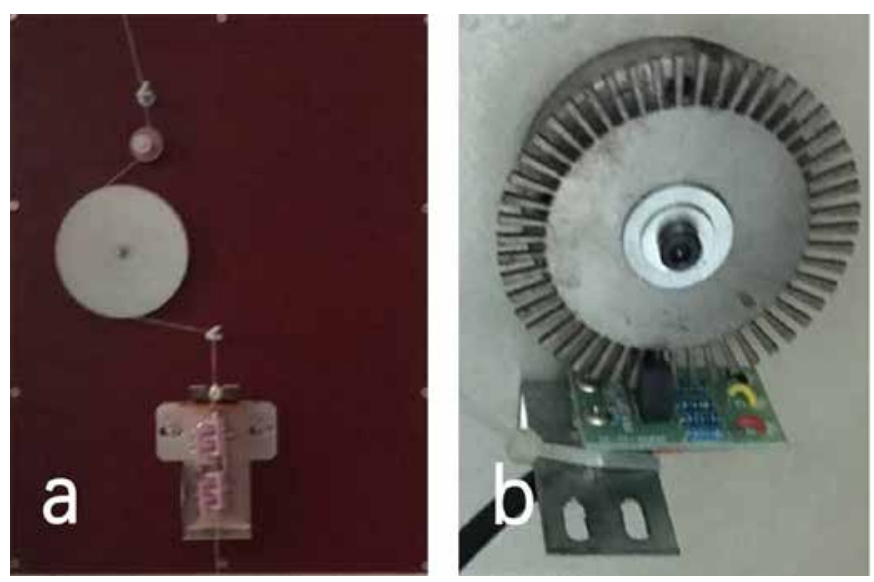

(a) length-counting disk and (b) coded disk

Figure 5. Images of electronic length-counting device

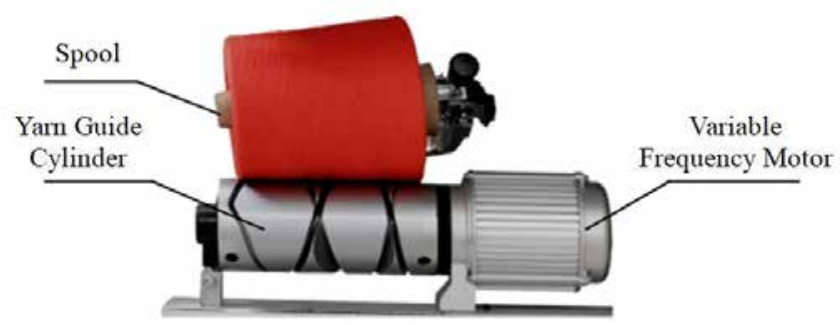

Figure 6. Yarn recovery unit 
the weighing result of the electronic balance is not affected by the yarn tension. Transmit the mass $G_{s}$ of the yarn sample to be tested after winding to the computing control unit after the electronic balance is stabilized.

5. The Windows CE human-machine dialogue system automatically calculates the linear density value of the yarn under testing according to formula 1 based on the mass difference $\Delta G$ before and after yarn winding, the set yarn length $L$, and the actual moisture regain $W_{s}$. The previous testing procedures will be automatically repeated until the testing data of the $\mathrm{N}_{\text {th }}$ sample are obtained, and the linear density unevenness $C V$ between fragments of the yarn under testing is calculated according to formula 2 (or formula 3 ).

$\mathrm{N}_{\mathrm{tex}}=\frac{\left(\mathrm{G}_{\mathrm{f}}-\mathrm{G}_{\mathrm{s}}\right)}{\mathrm{L}} \times \frac{1+\mathrm{W}_{\mathrm{k}}}{1+\mathrm{W}_{\mathrm{s}}} \times 1000$

where $N_{\text {tex }}$ is the yarn linear density (Tex), $G_{f}$ is the yarn mass $(\mathrm{g})$ before winding, $G_{s}$ is the yarn mass $(\mathrm{g})$ after winding, $W_{k}$ is the commercial moisture regain (\%) of the yarn, and $W_{s}$ is the actual moisture regain of the yarn.

$\mathrm{CV}=\frac{\sqrt{\frac{\sum_{i=1}^{N}\left(\Delta \mathrm{G}_{1}-\overline{\Delta \mathrm{G}_{1}}\right)^{2}}{\mathrm{~N}}}}{\overline{\Delta \mathrm{G}}} \times 100 \%$

where $C V$ is the linear density unevenness (\%) between fragments, $\Delta G_{i}$ is the testing mass $(\mathrm{g})$ of each group of yarn, and $\overline{\Delta G}$ is the average value of testing mass $(\mathrm{g})$ of each group of yarn. Formula 3 shall be used for calculation when the test sample is less than 50 times.

$\mathrm{CV}=\frac{\sqrt{\frac{\sum_{i=1}^{N}(\Delta \mathrm{G}-\overline{\Delta G})^{2}}{N-1}}}{\overline{\Delta G}} \times 100 \%$

\section{Results and discussion}

\subsection{Analysis of testing accuracy}

The linear density value of the yarn sample is tested as the arbitration value according to the operational requirements specified in GB/T 29256.5-2012 Textiles - Woven Fabrics Construction - Method of Analysis - Part 5: Determination of Linear Density of Yarn Removed from Fabric. The real length of the yarn sample can be tested by means of a sample holding assembly on a yarn twist counter, or a simple self-built device. After being straightened under the pre-tension specified by the

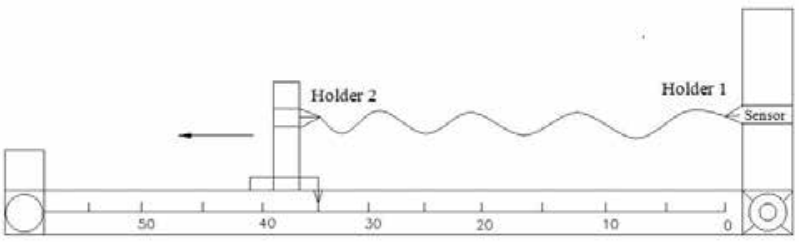

standard, the yarn between the two holding ends can be cut off by a blade as a yarn sample with known length.

As shown in Figure 7, both ends of a yarn sample are clamped on two holders, the distance between the holders is $L(m)$, and the holder 2 is moved leftward to gradually straighten the yarn sample until the tension value sensed by a sensor reaches the pre-tension value specified in the standard. At this point, the yarn is straightened but not elongated, and the moving distance of the holder 2 plus $L(m)$ is the length of the yarn between the two holders. Cut off the yarn sample by a blade as a test sample, weigh the sample and then calculate the linear density.

In this paper, polyester/viscose (65/35) blended yarn was used as a sample to test the linear density and unevenness. The results are shown in Table 1 to Table 6.

Linear density test data of polyester/viscose $65 / 35$ blended yarn are shown in Table 1. As can be seen from the data in the red box in Table 1, the average value of linear density measured by the developed device is less than the measurement value of the yarn length tester and is close to the arbitration value data, indicating that the electronic length-counting unit used by the developed device can effectively overcome the problem of excessive results caused by yarn overlapping on the skein frame of the yarn length tester. At the same time, the results of linear density standard deviation show that the dispersion of measurement results of the developed device is consistent with that of the arbitration method, both of which are less than the dispersion of the measurement data of the yarn length tester, indicating that the developed device has higher stability.

In statistics, significant difference is commonly used to evaluate the data difference. It is generally believed that there is a statistical difference between data when $P$ is less than 0.05 , there is a significant statistical difference between data when $P$ is less than 0.01 , and there is an extremely significant statistical difference between data when $P$ is less than 0.001. SPSS 25.0 software is used to compare the significant difference between the two sets of yarn linear density measured by the yarn length tester and the developed device, and the results are shown in Table 2.

In SPSS software, Sig is the abbreviation of Significance, so in SPSS software, the Sig value is the $P$ value $[18,19]$. As can be seen from the data in the red circle in Table 2, the Sig value ( $P$ value) next to $F$ is 0.000138 , which is obviously less than 0.001 , indicating that there is an extremely significant

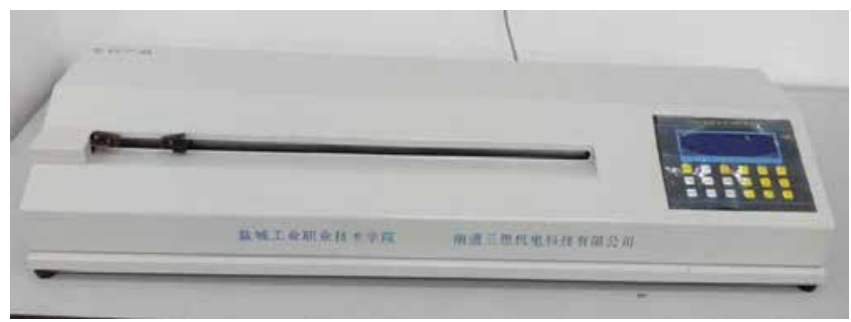

Figure 7. Real length test device of yarn sample (left: structure chart, right: physical picture) 
Table 1. Liner density results of polyester/viscose 65/35 blended yarn (Tex)

\begin{tabular}{|c|c|c|c|c|c|c|c|}
\hline $\begin{array}{c}\text { Experiment } \\
\text { Number }\end{array}$ & $\begin{array}{l}\text { Ntex } \\
\text { (Yarn } \\
\text { Length } \\
\text { Tester) }\end{array}$ & $\begin{array}{c}\text { Ntex } \\
\text { (Developed } \\
\text { Device) }\end{array}$ & $\begin{array}{c}\text { Ntex } \\
\text { (Abitration } \\
\text { Value) }\end{array}$ & $\begin{array}{c}\text { Experiment } \\
\text { Number }\end{array}$ & $\begin{array}{c}\text { Ntex (Yarn } \\
\text { Length } \\
\text { Teste) }\end{array}$ & $\begin{array}{c}\text { Ntex } \\
\text { (Developed } \\
\text { Device) }\end{array}$ & $\begin{array}{c}\text { Ntex } \\
\text { (Abitration } \\
\text { Value) }\end{array}$ \\
\hline 1 & 38.96 & 37.68 & 37.59 & 51 & 38.76 & 37.45 & 37.38 \\
\hline 2 & 38.66 & 37.54 & 37.59 & 52 & 39.05 & 37.63 & 37.64 \\
\hline 3 & 39.11 & 37.82 & 37.60 & 53 & 39.20 & 37.86 & 37.46 \\
\hline 4 & 38.64 & 37.47 & 37.44 & 54 & 38.84 & 37.63 & 37.34 \\
\hline 5 & 38.92 & 37.85 & 37.46 & 55 & 38.87 & 37.46 & 37.56 \\
\hline 6 & 39.09 & 37.51 & 37.67 & 56 & 39.19 & 37.50 & 37.54 \\
\hline 7 & 38.81 & 37.48 & 37.67 & 57 & 39.14 & 37.62 & 37.59 \\
\hline 8 & 39.11 & 37.43 & 37.48 & 58 & 38.51 & 37.89 & 37.32 \\
\hline 9 & 38.66 & 37.75 & 37.45 & 59 & 38.65 & 37.78 & 37.78 \\
\hline 10 & 39.03 & 37.49 & 37.59 & 60 & 38.96 & 37.72 & 37.50 \\
\hline 11 & 38.51 & 37.58 & 37.37 & 61 & 39.20 & 37.82 & 37.79 \\
\hline 12 & 38.72 & 37.66 & 37.44 & 62 & 38.71 & 37.47 & 37.70 \\
\hline 13 & 38.60 & 37.88 & 37.46 & 63 & 38.51 & 37.81 & 37.74 \\
\hline 14 & 39.05 & 37.85 & 37.74 & 64 & 38.58 & 37.63 & 37.66 \\
\hline 15 & 38.75 & 37.74 & 37.32 & 65 & 38.52 & 37.67 & 37.58 \\
\hline 16 & 39.15 & 37.81 & 37.52 & 66 & 38.78 & 37.83 & 37.48 \\
\hline 17 & 38.89 & 37.51 & 37.37 & 67 & 39.16 & 37.42 & 37.73 \\
\hline 18 & 39.11 & 37.50 & 37.51 & 68 & 38.88 & 37.74 & 37.64 \\
\hline 19 & 39.11 & 37.70 & 37.50 & 69 & 38.71 & 37.44 & 37.60 \\
\hline 20 & 38.77 & 37.44 & 37.37 & 70 & 38.97 & 37.42 & 37.35 \\
\hline 21 & 38.88 & 37.65 & 37.79 & 71 & 38.79 & 37.86 & 37.40 \\
\hline 22 & 38.99 & 37.81 & 37.48 & 72 & 39.18 & 37.81 & 37.76 \\
\hline 23 & 38.54 & 37.43 & 37.79 & 73 & 38.98 & 37.89 & 37.42 \\
\hline 24 & 38.78 & 37.73 & 37.35 & 74 & 38.60 & 37.71 & 37.60 \\
\hline 25 & 38.94 & 37.76 & 37.37 & 75 & 38.66 & 37.52 & 37.44 \\
\hline 26 & 38.60 & 37.65 & 37.35 & 76 & 39.13 & 37.74 & 37.75 \\
\hline 27 & 38.96 & 37.65 & 37.76 & 77 & 38.84 & 37.47 & 37.49 \\
\hline 28 & 38.88 & 37.78 & 37.40 & 78 & 39.18 & 37.72 & 37.50 \\
\hline 29 & 38.88 & 37.81 & 37.66 & 79 & 38.79 & 37.88 & 37.66 \\
\hline 30 & 38.56 & 37.88 & 37.60 & 80 & 38.69 & 37.70 & 37.44 \\
\hline 31 & 38.65 & 37.55 & 37.47 & 81 & 39.20 & 37.78 & 37.53 \\
\hline 32 & 38.76 & 37.75 & 37.64 & 82 & 39.14 & 37.72 & 37.39 \\
\hline 33 & 38.64 & 37.41 & 37.48 & 83 & 38.73 & 37.71 & 37.80 \\
\hline 34 & 38.64 & 37.41 & 37.79 & 84 & 38.78 & 37.66 & 37.72 \\
\hline 35 & 39.18 & 37.64 & 37.33 & 85 & 39.03 & 37.62 & 37.75 \\
\hline 36 & 39.16 & 37.88 & 37.65 & 86 & 38.67 & 37.54 & 37.76 \\
\hline 37 & 38.86 & 37.86 & 37.60 & 87 & 38.55 & 37.81 & 37.65 \\
\hline 38 & 38.66 & 37.76 & 37.38 & 88 & 39.12 & 37.82 & 37.59 \\
\hline 39 & 39.00 & 37.45 & 37.71 & 89 & 38.66 & 37.76 & 37.44 \\
\hline 40 & 38.97 & 37.42 & 37.31 & 90 & 38.82 & 37.60 & 37.63 \\
\hline 41 & 39.01 & 37.63 & 37.60 & 91 & 38.53 & 37.72 & 37.60 \\
\hline 42 & 38.72 & 37.70 & 37.57 & 92 & 39.14 & 37.59 & 37.38 \\
\hline 43 & 38.93 & 37.84 & 37.45 & 93 & 38.84 & 37.84 & 37.38 \\
\hline 44 & 39.18 & 37.52 & 37.66 & 94 & 39.02 & 37.82 & 37.70 \\
\hline 45 & 38.85 & 37.52 & 37.42 & 95 & 38.85 & 37.83 & 37.59 \\
\hline 46 & 38.74 & 37.81 & 37.32 & 96 & 38.53 & 37.50 & 37.80 \\
\hline 47 & 38.77 & 37.74 & 37.72 & 97 & 39.12 & 37.71 & 37.72 \\
\hline 48 & 38.94 & 37.85 & 37.55 & 98 & 38.59 & 37.88 & 37.62 \\
\hline 49 & 38.51 & 37.46 & 37.77 & 99 & 39.09 & 37.45 & 37.42 \\
\hline 50 & 38.61 & 37.74 & 37.31 & 100 & 38.91 & 37.48 & 37.67 \\
\hline \multicolumn{5}{|c|}{ Average Value } & 38.86 & 37.67 & 37.55 \\
\hline \multicolumn{5}{|c|}{ Standard Deviation } & 0.21 & 0.15 & 0.15 \\
\hline
\end{tabular}


Table 2. Independent sample tests between yarn length tester group and developed device group (polyester/viscose blended yarn)

\begin{tabular}{|c|c|c|c|c|c|c|c|c|c|c|}
\hline & \multicolumn{3}{|c|}{$\begin{array}{c}\text { Levene's Variance Equivalence } \\
\text { Test }\end{array}$} & \multicolumn{7}{|c|}{ Mean Equivalence $t$ Test } \\
\hline & & & & & & & & & $\begin{array}{r}95 \% \mathrm{C} \\
\text { Interval o }\end{array}$ & $\begin{array}{l}\text { fidence } \\
\text { ifference }\end{array}$ \\
\hline & & $\mathbf{F}$ & Significance & $\mathbf{t}$ & $\begin{array}{c}\text { Degree } \\
\text { of } \\
\text { Freedom }\end{array}$ & $\begin{array}{l}\text { Sig. } \\
\text { (2-tailed) }\end{array}$ & $\begin{array}{c}\text { Mean } \\
\text { Difference }\end{array}$ & $\begin{array}{l}\text { Standard } \\
\text { Error } \\
\text { Difference }\end{array}$ & $\begin{array}{l}\text { Lower } \\
\text { Limit }\end{array}$ & $\begin{array}{l}\text { Upper } \\
\text { Limit }\end{array}$ \\
\hline \multirow{2}{*}{$\begin{array}{l}\text { Linear } \\
\text { Density }\end{array}$} & $\begin{array}{c}\text { Equal } \\
\text { Variances } \\
\text { Assumed }\end{array}$ & 15.121 & 0.000138 & 45.677 & 198 & $\begin{array}{l}4.2104 \mathrm{E}- \\
107\end{array}$ & 1.19080 & 0.02607 & 1.13939 & 1.24221 \\
\hline & $\begin{array}{c}\text { Equal } \\
\text { Variances } \\
\text { Not } \\
\text { Assumed }\end{array}$ & & & 45.677 & 178.921 & $\begin{array}{l}1.4646 \mathrm{E}- \\
100\end{array}$ & 1.19080 & 0.02607 & 1.13939 & 1.24224 \\
\hline
\end{tabular}

Table 3. Independent sample tests between developed device group and the arbitration group (polyester/viscose blended yarn)

\begin{tabular}{|c|c|c|c|c|c|c|c|c|c|c|}
\hline & \multicolumn{3}{|c|}{$\begin{array}{c}\text { Levene's Variance Equivalence } \\
\text { Test }\end{array}$} & \multicolumn{7}{|c|}{ Mean Equivalence $t$ Test } \\
\hline & & \multirow[b]{2}{*}{$\mathbf{F}$} & \multirow[b]{2}{*}{ Significance } & \multirow[b]{2}{*}{$\mathbf{t}$} & \multirow[b]{2}{*}{$\begin{array}{l}\text { Degree of } \\
\text { Freedom }\end{array}$} & \multirow[b]{2}{*}{$\begin{array}{c}\text { Sig. } \\
\text { (2-tailed) }\end{array}$} & \multirow[b]{2}{*}{$\begin{array}{c}\text { Mean } \\
\text { Difference }\end{array}$} & \multirow[b]{2}{*}{$\begin{array}{c}\text { Standard } \\
\text { Error } \\
\text { Difference }\end{array}$} & \multicolumn{2}{|c|}{$\begin{array}{c}95 \% \text { Confidence } \\
\text { Interval of Difference }\end{array}$} \\
\hline & & & & & & & & & $\begin{array}{l}\text { Lower } \\
\text { Limit }\end{array}$ & $\begin{array}{l}\text { Upper } \\
\text { Limit }\end{array}$ \\
\hline \multirow{2}{*}{$\begin{array}{l}\text { Linear } \\
\text { Density }\end{array}$} & $\begin{array}{c}\text { Equal } \\
\text { Variances } \\
\text { Assumed }\end{array}$ & 0.249 & 0.618 & 5.384 & 198 & $2.0492 \mathrm{E}-7$ & 0.11310 & 0.02101 & 0.07168 & 0.15452 \\
\hline & $\begin{array}{c}\text { Equal } \\
\text { Variances } \\
\text { Not } \\
\text { Assumed }\end{array}$ & & & 5.384 & 197.725 & $2.0519 \mathrm{E}-7$ & 0.11310 & 0.02101 & 0.07168 & 0.15452 \\
\hline
\end{tabular}

statistical difference between the variances of the two sets of data measured by the yarn length tester and the developed device. In other words, it is considered that the assumed variances are not equal. In this case, we only need to pay attention to the data in the red box in the table. In the red box in Table 2, Sig (2-tailed) is 1.4646E-100, which is obviously less than 0.001 , that is, $P$ value is less than 0.001 , indicating that there is an extremely significant statistical difference between the two sets of data measured by the yarn length tester and the developed device. The statistical analysis results show that unlike the traditional method using the yarn length tester, the developed device uses a different measuring principle to test the linear density of polyester/viscose blended yarn, so there is a significant difference between the two sets of test data.

Table 3 shows the significant difference between the two sets of yarn linear density measured by the developed device and the arbitration method. As can be seen from the data in the red circle, the Sig value next to $F$ is 0.618 , which is obviously much larger than 0.05 , indicating that there is no statistical difference between the variances of the two sets of data measured by the developed device and the arbitration method. The statistical analysis results show that there is no statistical difference between the developed device and the arbitration method during the measurement of the linear density of polyester/ viscose blended yarn.

Table 4 shows the test data of weight unevenness of polyester/ viscose $65 / 35$ blended yarn. As can be seen from the data in the red box, the average value of linear density unevenness measured by the developed device is less than the test data of the yarn length tester and is consistent with the arbitration value data. At the same time, the results of linear density unevenness standard deviation show that the dispersion of measurement results of the developed device is consistent with that of the arbitration method, both of which are less than the dispersion of the measurement data of the yarn length tester, indicating that the developed device has higher stability.

Table 5 shows the significant difference between the two sets of yarn linear density unevenness measured by the yarn length tester and the developed device. As can be seen from the data in the red circle, the Sig value ( $P$ value) next to $F$ is $2.9024 \mathrm{E}-15$, which is obviously less than 0.001 , indicating that there is an extremely significant statistical difference between the variances of the two sets of data measured by the yarn length tester and the developed device. In other words, it is considered that the assumed variances are not equal. In this 
Table 4. CV results of polyester/viscose $65 / 35$ blended yarn (\%)

\begin{tabular}{|c|c|c|c|c|c|c|c|}
\hline $\begin{array}{c}\text { Experiment } \\
\text { Number }\end{array}$ & $\begin{array}{l}\text { CV (Yarn } \\
\text { Length } \\
\text { Teste) }\end{array}$ & $\begin{array}{c}\text { CV } \\
\text { (Developed } \\
\text { Device) }\end{array}$ & $\begin{array}{c}\text { CV } \\
\text { (Arbitration } \\
\text { Value) }\end{array}$ & $\begin{array}{c}\text { Experiment } \\
\text { Number }\end{array}$ & $\begin{array}{l}\text { CV (Yarn } \\
\text { Length } \\
\text { Teste) }\end{array}$ & $\begin{array}{c}\text { CV } \\
\text { (Developed } \\
\text { Device) }\end{array}$ & $\begin{array}{c}\text { CV } \\
\text { (Abitration } \\
\text { Value) }\end{array}$ \\
\hline 1 & 0.93 & 0.44 & 0.41 & 51 & 0.82 & 0.44 & 0.55 \\
\hline 2 & 0.71 & 0.43 & 0.46 & 52 & 0.84 & 0.45 & 0.51 \\
\hline 3 & 0.83 & 0.44 & 0.46 & 53 & 0.77 & 0.49 & 0.55 \\
\hline 4 & 0.97 & 0.55 & 0.42 & 54 & 0.87 & 0.50 & 0.57 \\
\hline 5 & 0.88 & 0.60 & 0.53 & 55 & 0.73 & 0.56 & 0.46 \\
\hline 6 & 0.65 & 0.42 & 0.56 & 56 & 0.89 & 0.44 & 0.49 \\
\hline 7 & 0.87 & 0.49 & 0.58 & 57 & 0.61 & 0.59 & 0.53 \\
\hline 8 & 0.90 & 0.53 & 0.59 & 58 & 0.61 & 0.49 & 0.57 \\
\hline 9 & 0.65 & 0.59 & 0.48 & 59 & 0.57 & 0.43 & 0.51 \\
\hline 10 & 0.90 & 0.43 & 0.40 & 60 & 0.57 & 0.55 & 0.39 \\
\hline 11 & 0.96 & 0.57 & 0.43 & 61 & 0.98 & 0.43 & 0.46 \\
\hline 12 & 0.88 & 0.48 & 0.43 & 62 & 0.60 & 0.43 & 0.48 \\
\hline 13 & 0.66 & 0.59 & 0.57 & 63 & 0.69 & 0.50 & 0.51 \\
\hline 14 & 0.97 & 0.43 & 0.39 & 64 & 0.86 & 0.49 & 0.53 \\
\hline 15 & 0.86 & 0.43 & 0.41 & 65 & 0.86 & 0.49 & 0.40 \\
\hline 16 & 0.95 & 0.58 & 0.50 & 66 & 0.58 & 0.45 & 0.44 \\
\hline 17 & 0.95 & 0.47 & 0.52 & 67 & 0.85 & 0.56 & 0.46 \\
\hline 18 & 0.66 & 0.55 & 0.41 & 68 & 0.71 & 0.57 & 0.57 \\
\hline 19 & 0.72 & 0.43 & 0.42 & 69 & 0.93 & 0.59 & 0.40 \\
\hline 20 & 0.59 & 0.42 & 0.47 & 70 & 0.79 & 0.50 & 0.58 \\
\hline 21 & 0.67 & 0.47 & 0.55 & 71 & 0.63 & 0.54 & 0.47 \\
\hline 22 & 0.92 & 0.56 & 0.54 & 72 & 0.86 & 0.44 & 0.48 \\
\hline 23 & 0.71 & 0.58 & 0.53 & 73 & 0.73 & 0.57 & 0.46 \\
\hline 24 & 0.70 & 0.46 & 0.53 & 74 & 0.66 & 0.43 & 0.58 \\
\hline 25 & 0.65 & 0.40 & 0.45 & 75 & 0.97 & 0.40 & 0.46 \\
\hline 26 & 0.63 & 0.59 & 0.50 & 76 & 0.92 & 0.60 & 0.58 \\
\hline 27 & 0.61 & 0.57 & 0.58 & 77 & 0.69 & 0.57 & 0.42 \\
\hline 28 & 0.69 & 0.46 & 0.47 & 78 & 0.79 & 0.50 & 0.49 \\
\hline 29 & 0.61 & 0.46 & 0.43 & 79 & 0.92 & 0.49 & 0.56 \\
\hline 30 & 0.74 & 0.50 & 0.44 & 80 & 0.95 & 0.51 & 0.41 \\
\hline 31 & 0.67 & 0.50 & 0.49 & 81 & 0.94 & 0.59 & 0.57 \\
\hline 32 & 0.79 & 0.49 & 0.45 & 82 & 0.90 & 0.52 & 0.52 \\
\hline 33 & 0.56 & 0.42 & 0.44 & 83 & 0.56 & 0.49 & 0.40 \\
\hline 34 & 0.88 & 0.53 & 0.45 & 84 & 0.71 & 0.48 & 0.55 \\
\hline 35 & 0.86 & 0.44 & 0.43 & 85 & 0.74 & 0.52 & 0.50 \\
\hline 36 & 0.70 & 0.41 & 0.40 & 86 & 0.63 & 0.47 & 0.58 \\
\hline 37 & 0.60 & 0.54 & 0.46 & 87 & 0.73 & 0.41 & 0.44 \\
\hline 38 & 0.72 & 0.40 & 0.45 & 88 & 0.63 & 0.46 & 0.59 \\
\hline 39 & 0.69 & 0.47 & 0.57 & 89 & 0.66 & 0.60 & 0.44 \\
\hline 40 & 0.78 & 0.58 & 0.53 & 90 & 0.65 & 0.56 & 0.57 \\
\hline 41 & 0.85 & 0.48 & 0.44 & 91 & 0.78 & 0.46 & 0.43 \\
\hline 42 & 0.57 & 0.46 & 0.49 & 92 & 0.58 & 0.49 & 0.57 \\
\hline 43 & 0.74 & 0.50 & 0.52 & 93 & 0.76 & 0.47 & 0.54 \\
\hline 44 & 0.70 & 0.57 & 0.49 & 94 & 0.71 & 0.44 & 0.57 \\
\hline 45 & 0.68 & 0.51 & 0.55 & 95 & 0.85 & 0.60 & 0.56 \\
\hline 46 & 0.78 & 0.59 & 0.57 & 96 & 0.91 & 0.59 & 0.55 \\
\hline 47 & 0.97 & 0.54 & 0.50 & 97 & 0.71 & 0.47 & 0.53 \\
\hline 48 & 0.95 & 0.57 & 0.55 & 98 & 0.82 & 0.56 & 0.55 \\
\hline 49 & 0.87 & 0.44 & 0.50 & 99 & 0.66 & 0.57 & 0.57 \\
\hline 50 & 0.56 & 0.60 & 0.53 & 100 & 0.78 & 0.53 & 0.51 \\
\hline \multicolumn{5}{|c|}{ Average Value } & 0.76 & 0.50 & 0.50 \\
\hline \multicolumn{5}{|c|}{ Standard Deviation } & 0.12 & 0.06 & 0.06 \\
\hline
\end{tabular}


Table 5. Independent sample tests between yarn length tester group and developed device group (polyester/viscose blended yarn)

\begin{tabular}{|c|c|c|c|c|c|c|c|c|c|c|}
\hline & \multicolumn{3}{|c|}{$\begin{array}{c}\text { Levene's Variance Equivalence } \\
\text { Test }\end{array}$} & \multicolumn{7}{|c|}{ Mean Equivalence $t$ Test } \\
\hline & & \multirow[b]{2}{*}{$\mathbf{F}$} & \multirow[b]{2}{*}{ Significance } & \multirow[b]{2}{*}{$\mathbf{t}$} & \multirow[b]{2}{*}{$\begin{array}{c}\text { Degree } \\
\text { of } \\
\text { Freedom }\end{array}$} & \multirow[b]{2}{*}{$\begin{array}{c}\text { Sig. } \\
\text { (2-tailed) }\end{array}$} & \multirow[b]{2}{*}{$\begin{array}{c}\text { Mean } \\
\text { Difference }\end{array}$} & \multirow[b]{2}{*}{$\begin{array}{l}\text { Standard } \\
\text { Error } \\
\text { Difference }\end{array}$} & \multicolumn{2}{|c|}{$\begin{array}{c}95 \% \text { Confidence } \\
\text { Interval of Difference }\end{array}$} \\
\hline & & & & & & & & & $\begin{array}{l}\text { Lower } \\
\text { Limit }\end{array}$ & $\begin{array}{l}\text { Upper } \\
\text { Limit }\end{array}$ \\
\hline \multirow{2}{*}{$\begin{array}{c}\text { Weight } \\
\text { Unevenness }\end{array}$} & \begin{tabular}{|c|} 
Equal \\
Variances \\
Assumed
\end{tabular} & 73.469 & $2.9024 \mathrm{E}-15$ & 18.705 & 198 & $\begin{array}{c}1.2246 \mathrm{E}- \\
45\end{array}$ & 0.26060 & 0.1393 & 0.23313 & 0.28807 \\
\hline & $\begin{array}{c}\text { Equal } \\
\text { Variances } \\
\text { Not } \\
\text { Assumed }\end{array}$ & & & 18.705 & 143.280 & $\begin{array}{c}2.7472 \mathrm{E}- \\
40\end{array}$ & 0.26060 & 0.1393 & 0.23306 & 0.28814 \\
\hline
\end{tabular}

Table 6. Independent sample tests between developed device group and the abitration group (polyester/viscose blended yarn)

\begin{tabular}{|c|c|c|c|c|c|c|c|c|c|c|}
\hline & \multicolumn{3}{|c|}{$\begin{array}{c}\text { Levene's Variance Equivalence } \\
\text { Test }\end{array}$} & \multicolumn{7}{|c|}{ Mean Equivalence $t$ Test } \\
\hline & & & & & & & & & $\begin{array}{r}95 \% \text { Co } \\
\text { Interval of }\end{array}$ & $\begin{array}{l}\text { idence } \\
\text { ifference }\end{array}$ \\
\hline & & $\mathbf{F}$ & Significance & $\mathbf{t}$ & $\begin{array}{l}\text { Degree of } \\
\text { Freedom }\end{array}$ & $\begin{array}{c}\text { Sig. } \\
\text { (2-tailed) }\end{array}$ & $\begin{array}{c}\text { Mean } \\
\text { Difference }\end{array}$ & $\begin{array}{c}\text { Standard } \\
\text { Error } \\
\text { Difference }\end{array}$ & $\begin{array}{l}\text { Lower } \\
\text { Limit }\end{array}$ & $\begin{array}{l}\text { Upper } \\
\text { Limit }\end{array}$ \\
\hline \multirow[b]{2}{*}{$\begin{array}{l}\text { Linear } \\
\text { Density }\end{array}$} & $\begin{array}{c}\text { Equal } \\
\text { Variances } \\
\text { Assumed }\end{array}$ & 0.043 & 0.836 & 0.658 & 198 & 0.511 & 0.00560 & 0.00851 & -0.01118 & 0.02238 \\
\hline & $\begin{array}{c}\text { Equal } \\
\text { Variances } \\
\text { Not } \\
\text { Assumed }\end{array}$ & & & 0.658 & 197.880 & 0.511 & 0.00560 & 0.00851 & -0.01118 & 0.02238 \\
\hline
\end{tabular}

case, we only need to pay attention to the data in the red box in the table. In the red box in Table 5, Sig (2-tailed) is 2.7472E-40, which is obviously less than 0.001 , that is, $P$ value is less than 0.001 , indicating that there is an extremely significant statistical difference between the two sets of data measured by the yarn length tester and the developed device. The statistical analysis results show that unlike the traditional method using the yarn length tester, the developed device uses a different measuring principle to test the linear density unevenness of polyester/ viscose blended yarn, so there is a significant difference between the two sets of test data.

Table 6 shows the significant difference between the two sets of yarn linear density unevenness measured by the developed device and the arbitration method. As can be seen from the data in the red circle, the Sig value next to $F$ is 0.836 , which is obviously much larger than 0.05 , indicating that there is no statistical difference between the variances of the two sets of data measured by the developed device and the arbitration method. The statistical analysis results show that there is no statistical difference between the developed device and the arbitration method during the measurement of the weight unevenness of polyester/viscose blended yarn.

\section{Conclusions}

The conventional measurement of linear density and linear density unevenness between fragments is carried out step by step in the mode of counting length first and then cutting and measuring weight $[20,21]$, which has high labor intensity and low efficiency and can easily result in secondary error. Yarn overlapping will lead to excessive results, and because length counting and weight measurement are carried out separately, the yarn sample is discontinuous and not worth recycling for utilization, resulting in serious waste of yarn. The developed device is so designed that the weight is measured first and then the length is counted. It reasonably integrates the weight measurement unit, length-counting unit, recovery unit, and control unit. The measurement can be carried out continuously, and especially when 30 to 50 groups of yarn fragments will undergo testing for linear density unevenness, the developed device has obvious advantages. Common polyester/viscose $65 / 35$ blended yarn was taken as a test sample and subjected to statistical analysis using SPSS software. Results show that the operation is simple, the whole experiment can be completed at one time, avoiding secondary error, the results are closer to the real value, and the raw materials can be recycled, saving labor and raw material costs. The developed device can replace the existing yarn length tester, and has high value for industrialization and popularization. 


\section{Acknowledgments}

Funding: This research was supported by [Construction Project of Integrated Platform for Integration of Industry and Education in Higher Vocational Education in Jiangsu Province, grant number: Education Department of Jiangsu Province (2019)26], [Jiangsu Province Higher Vocational Education High-level Major Group Construction Project-Modern Textile Technology Major Group], [2020 Jiangsu Province Higher Vocational Colleges Teachers Professional Leaders high-end Research (team visit research)],[2020 Jiangsu productionstudy-research Cooperation Project (BY2020336) ] [Qinglan Project of Educational Department of Jiangsu Province, grant number:Education Department of Jiangsu Province (2019)3].

\section{References}

[1] Li J., Zuo B., Wang C., Tu W. (2015). A Direct Measurement Method of Yarn Evenness Based on Machine Vision. Journal of Engineered Fibers and Fabrics, 10(4), 95-102.

[2] Shi F., Wang Y. (2009). An analysis of capacitive evenness measurement of blended yarns. Journal of the Textile Institute, 100(1), 57-63.

[3] Liu J., Jiang H., Pan R., Gao W., Xu M. (2012). Evaluation of yarn evenness in fabric based on image processing. Text Res J, 82(10), 1026-1037.

[4] Toda M., Grabowska K., Ciesielska-Wrobel I. (2017). Application of micro-computed tomography (micro-CT) to study unevenness of the structure of yarns. Text Res $\mathrm{J}$, 87(3), 351-368.

[5] Jin J., Wang J. (2013). On Yarn Unevenness Test and its Influence Factor Analysis. In: New Trends in Mechanical Engineering and Materials. Volume 251. Edited by Deng XC., Dong X. 460-+.

[6] Yan G-S., Su Y-H. (2011). Simulation and Prediction of the Unevenness of Drafted Yarn. In: Textile Bioengineering and Informatics Symposium Proceedings, Vols 1-3.. Edited by Li Y., Liu YF., Luo XN., Li JS. 1348-1351.

[7] Wang X., Hou R-M., Gao X-Y., Xin B-J. (2020). Research on Yarn Diameter and Unevenness Based on an Adaptive Median Filter Denoising Algorithm. Fibres \& Textiles in Eastern Europe, 28(1), 36-41.

[8] Lin Q., Yan G., Yu C. (2010). The Analysis of the Influence of Fiber Length Distribution on the Theoretical and Additional Unevenness of Yarn. Fibers and Polymers, 11(2), 266-270.
[9] Su C-I., Lai P-T. (2010). Evaluating the Unevenness of Stretch-Broken Tow in Tow-to-Yarn Direct Spinning. Fibers and Polymers, 11(4), 648-653.

[10] Bashkova G.V., Bashkov A.P. (2010). Mechanism of periodical unevenness emerging in open-end spun yarn. Industria Textila, 61(1), 7-10.

[11] Yan G., Zhu J., Yu C. (2010). A new approach to theoretical yarn unevenness: a binomial distribution model. Journal of the Textile Institute, 101(8), 753-757.

[12] Badehnoush A., Yazdi AA. (2012). Real-time yarn evenness investigation via evaluating spinning triangle area changes. Journal of the Textile Institute, 103(8), 850861.

[13] Yuan R., Jiang $X .:$ Research on on-line detection technology for yarn evenness. In: Advanced Measurement and Test, Pts 1-3. Volume 301-303. Edited by Esa R., Wu YW. 60-66.

[14] Gulsevincler E., Usal MR., Yilmaz D. (2020). Yarn evenness parameters optimization in jetring spinning process. Journal of the Textile Institute, 111(4), 540-549.

[15] Demiryurek O., Koc E. (2009). Predicting the unevenness of polyester/viscose blended open-end rotor spun yarns using artificial neural network and statistical models. Fibers and Polymers, 10(2), 237-245.

[16] Li H., Wang X., Natl Engn Res Ctr D, Finish Textiles; Minist Educ KLS, Technol Eco-Textile; Donghua Univ CCCE, Biotechnol (2010). Predicting Yarn Unevenness Using RBF Neural Network.

[17] Zhu J-Z., Yan G-S., Su Y-H. (2010). Study on the Relation between Theoretical and Tested Unevenness of Staple Yarn.

[18] Liang G, Fu W, Wang K. (2019). Analysis of t-test misuses and SPSS operations in medical research papers. Burns \& Trauma, 7(1).

[19] Bezzaouha A., Bouamra A., Ammimer A., Ben Abdelaziz A. (2020). Non-parametric tests on SPSS to compare two or more means on matched samples. La Tunisie medicale, 98(12), 932-941.

[20] Li Z., Pan R., Zhang J., Li B., Gao W., Bao W. (2016). Measuring the unevenness of yarn apparent diameter from yarn sequence images. Measurement Science and Technology, 27(1).

[21] Erbil Y., Babaarslan O., Ilhan I. (2015). Predicting the unevenness of polyester/viscose/acrylic-blended openend rotor spun yarns. Journal of the Textile Institute, 106(7), 699-705. 